\title{
Peningkatan Kapasitas Masyarakat Untuk Kesiap-siagaan dan Mitigasi Bencana Tsunami di Desa Borgo Kabupaten Minahasa
}

\author{
Gerald Tamuntuan $^{1^{*}}$, Guntur Pasau ${ }^{1}$, Esli Takumansang ${ }^{2}$ \\ ${ }^{1}$ Program Studi Fisika, Fakultas Matematika dan Ilmu Pengetahuan Alam \\ Universitas Sam Ratulangi \\ ${ }^{2}$ Program Studi Perencanaan Wilayah dan Kota, Fakultas Teknik \\ Universitas Sam Ratulangi \\ *Penulis Korespondensi, email: gtamuntuan@gmail.com
}

\begin{abstract}
ABSTRAK
Desa Borgo merupakan salah satu wilayah di Kabupaten Minahasa yang berlokasi di pesisir barat semenanjung utara Pulau Sulawesi. Desa ini ke arah barat berhadapan langsung dengan Laut Sulawesi yang merupakan salah satu daerah sumber gempa di Indonesia. Sumber gempa di Laut Sulawesi umumnya memiliki hiposenter disekitar subduksi Laut Sulawesi dengan kedalaman yang relatif dangkal sehingga sangat berpotensi tsunami. Menjadi permasalahan adalah bahwa pemerintah dan masyarakat di Desa Borgo Kabupaten Minahasa belum tanggap terhadap bahaya tsunami. Hal ini didasarkan pada hasil analisis situasi yang menunjukkan bahwa tingkat pengetahuan yang benar dari masyarakat tentang tsunami masih kurang, belum adanya koordinasi antara pemerintah dan masyarakat, belum terbentuknya kelompok/satuan tugas yang bertanggungjawab terhadap proses evakuasi warga, serta belum adanya tanda-tanda atau piktogram tsunami dan peta jalur evakuasi. Oleh karena itu telah dilaksanakan program kemitraan untuk pemberdayaan kelompok masyarakat dan pemerintah desa dalam rangka mengatasi masalah prioritas yang ada. Metode yang digunakan dalam penyelesaian masalah berbentuk penyuluhan/sosialisasi dan pelatihan dalam rangka membangun budaya kesiap-siagaan serta kemampuan mitigasi bencana tsunami bagi masyarakat Desa Borgo Kabupaten Minahasa. Disamping telah dilakukan juga penyediaan sejumlah barang untuk mendukung proses mitigasi serta evakuasi saat terjadi bencana tsunami antara lain seperti peta potensi/bahaya tsunami, peta jalur evakuasi, rambu petunjuk arah evakuasi, megaphone, dan head lamp. Hasil evaluasi yang dilakukan dalam bentuk tes sebelum dan sesudah pemberian materi sosialisasi menunjukkan adanya peningkatan pengetahuan dalam membangun kesiap-siagaan dan mitigasi bencana tsunami.
\end{abstract}

Kata kunci: Kesiap-siagaan, Mitigasi, Tsunami, Borgo

\section{PENDAHULUAN}

\section{Analisis Situasi}

Desa Borgo merupakan salah satu desa di Kabupaten Minahasa yang berlokasi di pantai barat semenanjung utara Pulau Sulawesi. Desa ini memiliki luas sekitar 9 ha dimana sebelah utara berbatasan dengan Desa Tambala, sebelah timur berbatasan dengan Desa Sarani Matani, sebelah selatan berbatasan dengan Desa Ranowangko, sedangkan sebelah barat berbatasan dengan pantai laut sulawesi. Menurut statistik desa, jumlah penduduk berkisar 1855 jiwa dengan prosentase terbesar pekerjaan masyarakat adalah nelayan, diikuti oleh petani, pegawai negeri sipil (PNS), dan lain-lain. Lebih dari $70 \%$ pemukiman masyarakat berada pada lokasi relatif datar dengan ketinggian dari permukaan laut berkisar antara $1-5 \mathrm{~m}$. Pada batas timur Desa Borgo terdapat bukit bernama Worong Sanger dengan ketinggian mencapai 80 m dari permukaan laut. Jarak dari pantai ke kaki bukit tersebut sekitar $300 \mathrm{~m}$.

Sulawesi Utara merupakan wilayah yang memiliki peluang terjadinya gempa bumi bermagnitudo besar (Frastika dkk, 2013) 
sehingga berstatus paling rawan jika dibandingkan dengan wilayah lainnya di Pulau Sulawesi. Walaupun intensitas perulangannya lebih kecil dibandingkan yang terjadi di wilayah Laut Maluku Hamzah dkk (2000), gempa-gempa di Laut Sulawesi memiliki potensi yang lebih besar dalam membangkitkan gelombang tsunami karena memiliki hiposenter dangkal. Di Laut Sulawesi, gempa pada umumnya terbangkit di sekitar lokasi subduksi laut Sulawesi dan memiliki kedalaman yang relatif dangkal yaitu kurang dari $50 \mathrm{~km}$ (Pasau \& Tanauma, 2015). Sejarah mencatat bahwa di zona subduksi Laut Sulawesi pernah terjadi gempa berkekuatan $\mathrm{Mw}$ 8,4 pada tahun 1904 (Pasau dkk, 2017). Hal-hal tersebut menunjukkan bahwa Desa Borgo yang berbatasan langsung dengan Laut Sulawesi di bagian barat merupakan daerah yang rawan dilanda bencana tsunami.

Gambar 1 menunjukkan hasil pemodelan penjalaran tsunami yang dilakukan oleh tim pengusul dengan skenario gempa magnitudo 8 SR terjadi di patahan laut Sulawesi. Skenario ini menggunakan data lokasi dan magnitudo tertinggi dari gempa yang pernah terjadi di laut Sulawesi. Hasil menunjukkan bahwa waktu tiba gelombang tsunami di Desa Borgo adalah sekitar 17 menit setelah gempa, dan ketinggian tsunami berkisar $3-4 \mathrm{~m}$. Kondisi ini tentunya menjadi ancaman serius bagi keselamatan masyarakat yang berada di Desa Borgo dan daerah sekitarnya. Untuk itu sangat perlu membangun sikap dan kesiap-siagaan tsunami untuk mitigasi bencana di Desa Borgo Kecamatan Tombariri Kabupaten Minahasa.

Berdasarkan survey pendahuluan diketahui bahwa masyarakat Desa Borgo belum tanggap terhadap potensi bahaya tsunami yang dapa melanda daerah tersebut. Adapun beberapa masalah yang teridentifikasi adalah sebagai berikut:

- Kurangnya pengetahuan dan kesadaran masyarakat tentang tsunami

- Belum adanya satuan/kelompok yang memiliki tugas khusus untuk koordinasi penyelamatan diri dan proses evakuasi
- Belum adanya konsep dan ketrampilan menyelamatkan diri yang terkoordinasi

- Tidak adanya piktogram/tanda-tanda jalur evakuasi

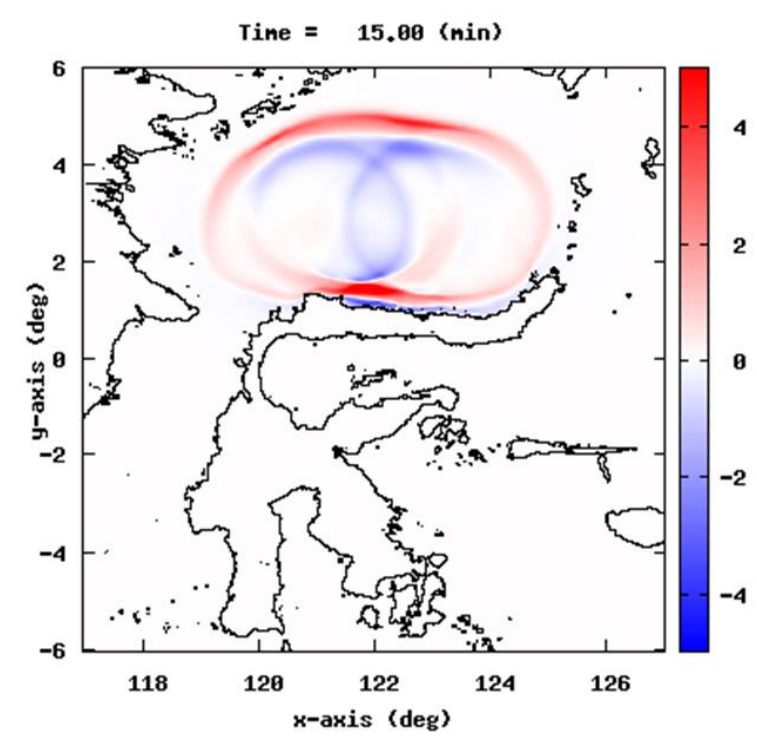

Gambar 1. Pemodelan penjalaran tsunami akibat gempa yang terjadi pada zona subduksi laut sulawesi.

\section{Tujuan dan Manfaat Kegiatan}

Untuk menyelesaikan permasalahanpermasalahan pada kelompok mitra maka telah dilaksanakan kegiatan Program Kemitraan Masyarakat (PKM) dengan tujuan dan manfaat untuk membangun sikap dan kondisi kesiapsiagaan tsunami masyarakat Desa Borgo melalui transfer pengetahuan dan ketrampilan tentang tanggap bencana tsunami serta membantu masyarakat mempersiapkan beberapa infrastruktur terkait evakuasi seperti peta evakuasi, rambu-rambu petunjuk arah evakuasi, dan perlengkapan sederhana yang berkaitan erat dengan proses evakuasi.

\section{METODE PELAKSANAAN}

\section{Sasaran kegiatan}

Sasaran pelaksanaan kegiatan pelatihan ini adalah pemerintah dan masyarakat Desa Borgo Kecamatan Tombariri Kabupaten Minahasa.

\section{Lokasi kegiatan}


VIVABIO

Jurnal Pengabdian Multidisiplin

Kegiatan secara umum dilaksanakan di Desa

Borgo Kecamatan Tombariri Kabupaten Minahasa.

\section{Metode yang digunakan :}

Metode ataupun tahap-tahap pelaksanaan kegiatan sebagai solusi untuk membangun kelompok masyarakat Desa Borgo yang siap siaga bencana tsunami adalah sebagai berikut:

a. Penyediaan/Pembuatan infrastruktur

Bagian ini dilakukan untuk melengkapi soft skill yang diberikan kepada masyarakat. Bentuk-bentuk kegiatan yang telah dilakukan adalah pembuatan peta potensi tsunami, pembuatan peta evakuasi, pembuatan dan pemasangan tanda-tanda untuk jalur evakuasi, penyediaan perlengkapan satgas seperti head lamp serta alat komunikasi massa elektronik (pengeras suara) seperti megaphone.

b. Penyuluhan

Kegiatan ini dilakukan dalam bentuk ceramah serta dialog interaktif dengan pemerintah serta sejumlah masyarakat. Materi disajikan dalam bentuk presentasi audiovisual agar lebih menarik dan lebih mudah dipahami oleh peserta.

c. Pelatihan Strategi Evakuasi

Skenario Run Down simulasi tsunami (Tsunami Drill) dibuat berdasarkan golden time, yaitu saat-saat genting penerbitan warning (peringatan) tsunami mulai terjadinya gempa sampai dengan saat akan terjadinya tsunami. Golden time ini memerlukan waktu 17 menit yaitu mulai terjadinya gempa sampai dengan terjadinya tsunami dimana diantara waktu-waktu tersebut BMKG akan menerbitkan peringatan yang sangat menentukan respons yang harus dilakukan. Perencanaan dan strategi akan didesain berdasarkan tiga fase kejadian berikut:

- Saat gempa terjadi dan pra tsunami

- Kepastian tsunami

- Respons darurat medik di lokasi evakuasi d. Evaluasi kegiatan

Evaluasi dilakukan dalam bentuk pre-test dan post-test terhadap materi yang diberikan.

\section{HASIL DAN PEMBAHASAN}

a. Koordinasi serta penyediaan infrastruktur

Pelaksanaan kegiatan diawali dengan tahap persiapan yang dilakukan oleh tim PKM melalui kegiatan-kegiatan sebagai berikut:

1. Perkunjungan dan koordinasi I dengan mitra dan pemerintah Desa Borgo pada bulan April tahun 2019.

2. Pelaksanaan Focus Group Discussion untuk persiapan materi presentasi dan pelatihan pada bulan Mei 2019.

3. Pembuatan peta potensi tsunami dan peta evakuasi pada bulan Juni 2019.

4. Persiapan barang-barang yang akan digunakan pada kegiatan sosialisasi dan dihibahkan ke masyarakat seperti pembelian head lamp, work light, megaphone pada bulan Juni - Juli 2019.

5. Survey lokasi dan pembuatan rambu evakuasi pada bulan Juli - Agustus 2019

6. Koordinasi pelaksanaan kegiatan sosialisasi dan pelatihan dengan pemerintah Desa Borgo

Gambar 2 dan Gambar 3 menunjukkan peta-peta yang telah dihasilkan, sedangkan Gambar 4 adalah beberapa alat pendukung yang telah diberikan kepada pemerintah dan masyarakat untuk mitigasi bencana tsunami di Desa Borgo Kabupaten Minahasa. 


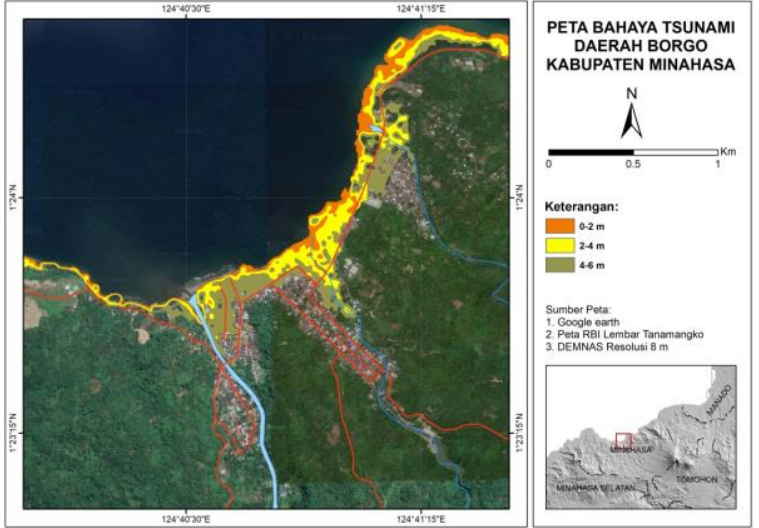

Gambar 2. Peta potensi bahaya tsunami dengan tiga kategori tinggi gelombang, yaitu $2 \mathrm{~m}, 4 \mathrm{~m}$, dan $6 \mathrm{~m}$.

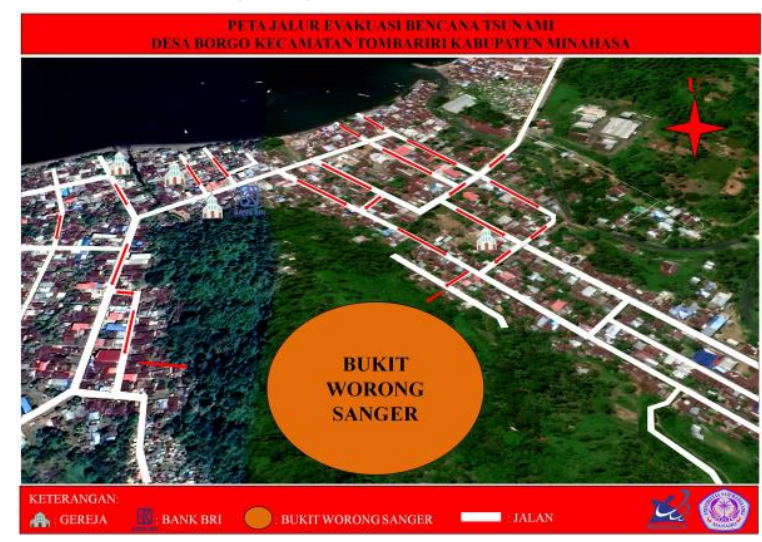

Gambar 3. Peta jalur evakuasi untuk Desa Borgo Kabupaten Minahasa.

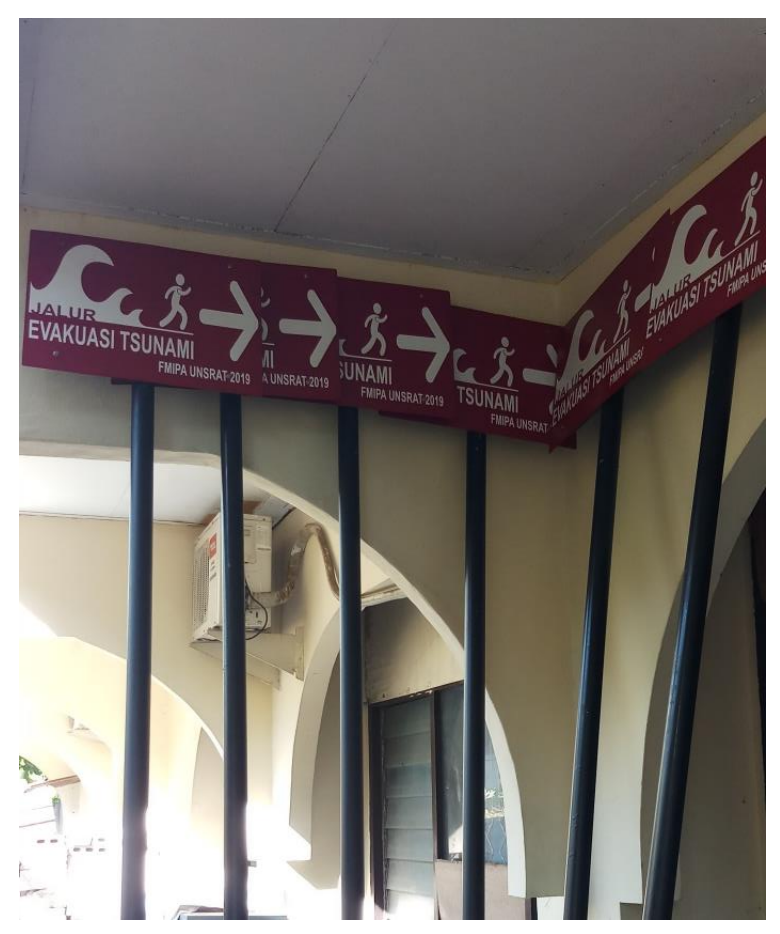

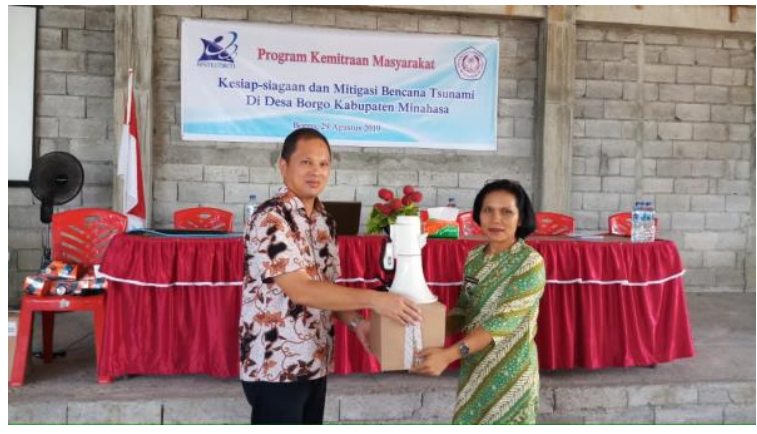

Gambar 4. (a) Petunjuk arah evakuasi, dan (b) megaphone (2 buah) serta head lamp (12 buah) yang telah diserahkan kepada pemerintah Desa Borgo Kabupaten Minahasa.

b. Penyuluhan dan pelatihan singkat strategi evakuasi.

Beberapa ciri dari masyarakat dan daerah yang tanggap tsunami antara lain adalah sudah terbentuknya pengetahuan dan ketrampilan menyelamatkan diri melalui latihan kesiapsiagaan, tersedianya tempat evakuasi beserta peta pencapaiannya, terpasangnya rambu-rambu petunjuk arah evakuasi (Rahayu $\mathrm{dkk}$, 2007). Oleh karena penyuluhan atau sosialiasi bertema Kesiap-siagaan dan Mitigasi Bencana Tsunami di Desa Borgo Kabupaten Minahasa telah dilaksanakan pada tanggal 29 Agustus 2019 bertempat di Balai Pertemuan Umum Desa Borgo Kabupaten Minahasa. Tim PKM berjumlah 10 orang yang terdiri atas 5 orang dosen dan 5 orang mahasiswa. Peserta yang hadir berjumlah 50 orang terdiri atas Kepala Desa, Sekretaris Desa, Perangkat Desa dan sejumlah masyarakat.

Kegiatan diawali dengan doa bersama dan dilanjutkan dengan sambutan masing-masing oleh Dr. Gerald Tamuntuan sebagai Ketua Tim Pelaksana PKM dan Ibu Temmy Rompas, S.Pd sebagai Kepala Desa Borgo. Acara berikutnya adalah penyajian materi sosialisasi yaitu:

1. Penyebab Gempa Bumi dan Tsunami oleh Guntur Pasau, S.Si., M.Si.

2. Perencanaan dan Strategi Evakuasi oleh Dr. Gerald Tamuntuan, S.Si., M.Si 
VIVABIO

Jurnal Pengabdian Multidisiplin

3. Pengenalan prinsip kedaruratan medik sederhana oleh Seni Tongkukut, S.Si., M.Si.

Pemerintah dan masyarakat yang hadir sangat antusias, terlihat dari keaktivan peserta dalam tanya jawab / diskusi. Kepala Desa dalam hal ini menyatakan sangat gembira dan memberikan apresiasi kepada tim PKM karena boleh menerima materi yang sangat berharga. Selesai penyajian materi, tim PKM menyerahkan beberapa peralatan kepada pemerintah desa untuk dilanjutkan kepada kelompok mitra yang akan diangkat menjadi satgas bencana di Desa Borgo. Beberapa peralatan yang diserahkan antara lain head lamp, working lamp, dan megaphone merk Toa. Peralatan megaphone dalam hal ini diberikan untuk mengantisipasi terjadinya pemadaman listrik saat kejadian bencana, sehingga diperlukan alat pengeras suara yang bersumber dari batere. Para mahasiswa dalam hal ini bertugas membantu nara sumber dan peserta dalam kelancaran acara. Beberapa dokumentasi pada saat kegiatan sosialisasi disajikan dalam Gambar 5.
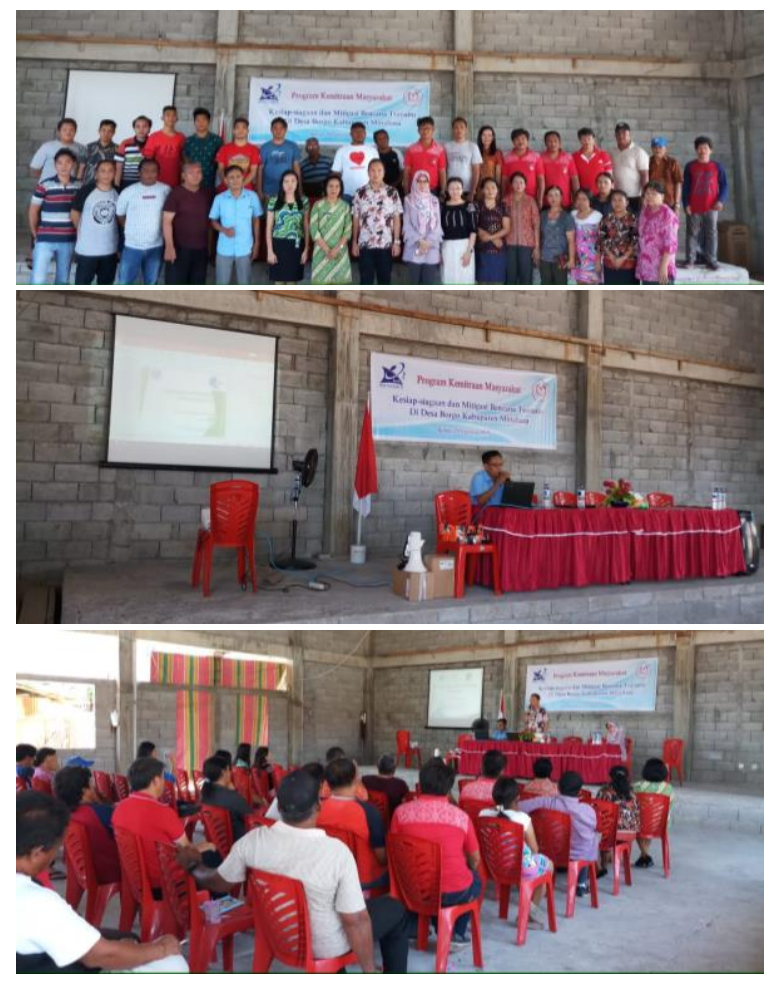

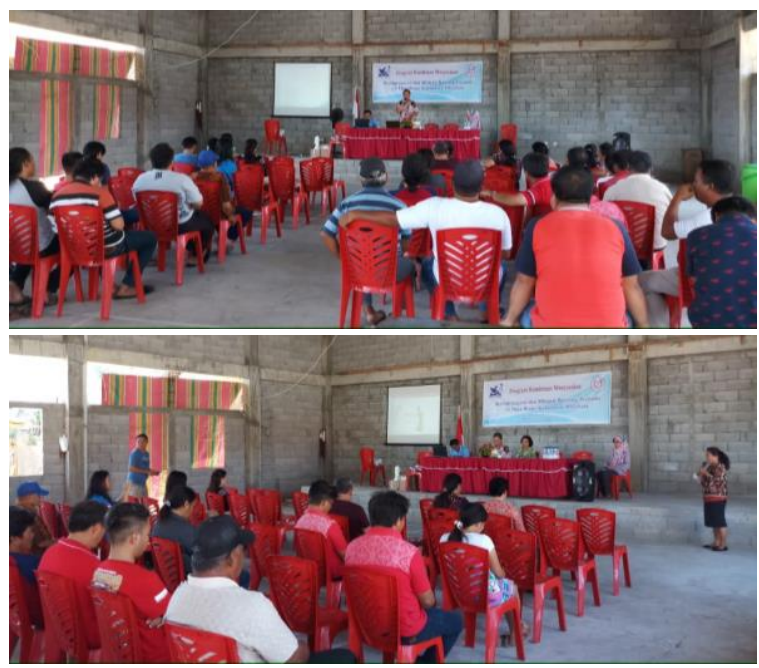

Gambar 5. Dokumentasi saat pelaksanaan sosialisasi kesiap-siagaan dan mitigasi bencana tsunami bertempat di Balai Pertemuan Umum Desa Borgo Kabupaten Minahasa.

Dalam rangkaian materi Perencanaan dan Strategi Evakuasi, pemerintah dan masyarakat telah diberikan sedikit latihan untuk melakukan proses simulasi evakuasi sesuai alur yang disajikan pada Gambar 6. Pemerintah dan masyarakat dimotivasi untuk terus melatih proses tersebut agar supaya menjadi terbiasa dan tanggap dalam melakukan mitigasi bencana tsunami.

\begin{tabular}{|c|c|}
\hline Persiapan & $00.00 .00-01.00 .00$ \\
\hline \multicolumn{2}{|l|}{ 2 } \\
\hline Terjadi gempa & $01.00 .00-01.00 .20$ \\
\hline \multicolumn{2}{|l|}{$\sqrt{2}$} \\
\hline Goncangan skala VI-VII MMI & $01.00 .20-01.01 .00$ \\
\hline & dirasakan oleh masyarakat \\
\hline - Respons Ketua Satgas & \multirow{2}{*}{$01.01 .00-01.05 .00$} \\
\hline - Masyarakat ke titik kumpul & \\
\hline Sirene evakuasi berbunvi & $010500-010800$ \\
\hline \multicolumn{2}{|l|}{$\sqrt{2}$} \\
\hline Respons satgas + proses evakuasi & $01.08 .00-01.17 .00$ \\
\hline \multicolumn{2}{|l|}{$\sqrt{2}$} \\
\hline Tiba di lokasi evakuasi & 01.17 .00 \\
\hline \multicolumn{2}{|l|}{$\sqrt{2}$} \\
\hline Emergency response di tempat evakuasi & $01.17 .00<\ldots$ \\
\hline
\end{tabular}

Gambar 6. Run down simulasi evakuasi berdasarkan waktu tiba gelombang tsunami di Desa Borgo Kabupaten Minahasa. 
c. Evaluasi kegiatan

Untuk mengukur peningkatan keberdayaan masyarakat dalam hal terbentuknya pengetahuan tentang bencana tsunami serta cara-cara menyelamatkan diri/kelompok dan proses evakuasi, maka telah dilakukan evaluasi kepada 20 orang yang ditentukan secara acak. Evaluasi dalam bentuk pemberian test sebelum dan sesudah materi disampaikan.

Gambar 7 memperlihatkan grafik antara responden dengan jumlah jawaban benar. Grafik tersebut menunjukkan bahwa sebelum menerima materi, jumlah jawaban benar dari para responden bervariasi antara 5 hingga 10 dengan rata-rata sekitar 7 , sedangkan setelah menerima materi meningkat menjadi 8 hingga 13 dengan rata-rata sekitar 12 .

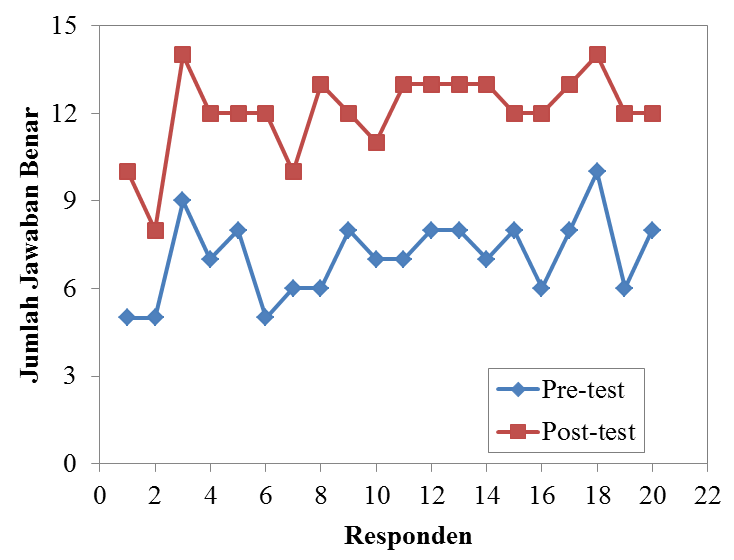

Gambar 7. Grafik jumlah jawaban benar -vsresponden.

Grafik pada Gambar 7 menunjukkan bahwa jumlah jawaban benar dari semua responden mengalami peningkatan. Hal ini mengindikasikan bahwa telah terjadi peningkatan pengetahuan tentang tsunami dan mitigasinya pada masyarakat Desa Borgo Kabupaten Minahasa.

\section{KESIMPULAN DAN SARAN}

Program Kemitraan Masyarakat (PKM) untuk membangun kesiap-siagaan dan kemampuan mitigasi tsunami di Desa Borgo
Kabupaten Minahasa telah dilakukan dalam bentuk sosialisasi/penyuluhan serta membantu masyarakat mempersiapkan beberapa infrastruktur terkait evakuasi seperti peta evakuasi, rambu-rambu petunjuk arah evakuasi, dan perlengkapan sederhana yang berkaitan erat dengan proses evakuasi. Hasil evaluasi menunjukan terjadinya peningkatan pengetahuan dan kemampuan pemerintah dan masyarakat Desa Borgo dalam mengantisipasi bahaya bencana tsunami.

\section{UCAPAN TERIMA KASIH}

Terima kasih diucapkan kepada Hukum Tua dan Perangkat Desa, serta masyarakat Desa Borgo Kabupaten Minahasa atas dukungan dan kerjasamanya dalam kegiatan PKM. Ucapan terima kasih juga disampaikan kepada DRPM Ristekdikti yang telah membiayai kegiatan pengabdian ini melalui skim Program Kemitraan Masyarakat (PKM) tahun 2019.

\section{DAFTAR PUSTAKA}

Frastika, Y., Pasau, G., Prang, J. 2013. Estimasi Periode Ulang Gempa Bumi di Wilayah Sulawesi dengan Menggunakan Distribusi Gumbel. Jurnal MIPA Unsrat Online Vol. 2 (2), 151-155.

Hamzah, L., Puspito, N.T., Imamura, F. 2000. Tsunami Catalog and Zones in Indonesia. Journal of Natural Disaster Science Vol. 22 (1), 25-43.

Pasau, G., Tanauma, A. 2015. Analisis Resiko Gempa Bumi Wilayah Lengan Utara Sulawesi Menggunakan Data Hiposenter Resolusi Tinggi Sebagai Upaya Mitigasi Bencana. Spektra: Jurnal Fisika dan Aplikasinya 16 (3): 6-10.

Pasau, G., Ferdy, Tamuntuan, G. 2017. Pengamatan Seismisitas Gempa Bumi di Wilayah Pulau Sulawesi Menggunakan Perubahan Nilai a - b. Jurnal MIPA Unsrat Online 6 (1): 31-35.

Rahayu, H.P., Wahdiny, I.I., Mariani, A. 2007. Pedoman Pelaksanaan Latihan Kesiapsiagaan Menghadapi Bencana Tsunami (Tsunami Drill) untuk Kota dan Kabupaten. 
Jurnal Pengabdian Multidisiplin

Kementerian Negara Riset dan Teknologi,

Jakarta. 109 p. 